\title{
La justicia militar en el Perú
}

Elmer Chirre Castillo* Beatriz Caballero Montero**

* Abogado, docente de la Universidad Alas Peruanas.

**Abogada, docente de la Universidad Alas Peruanas. 


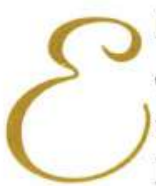

l estudio de la justicia militar ha constituido durante mucho tiempo un tema que ha dado lugar a la creencia que este debiera ser de preocupación exclusiva de los militares y de sus operadores jurídicos castrenses, sin embargo los hechos recientes que el país ha sufrido nos hace pensar que la atención hacia ella se debe extender al otro lado de la orilla, es decir a la otra fracción históricamente contrapuesta como resulta ser la civilidad, que salvo honrosas excepciones, ha pecado también al no ofrecer mucho esfuerzo en profundizar su conocimiento y dedicación en una lamentable complicidad con una triste realidad, como resulta ser la precaria producción bibliográfica del tema.

Un estado democrático moderno no tiene espacio para las arbitrariedades y abusos, menos aun cuando reiteradamente se demuestra que precisamente por no haber delineado bien esos márgenes y no tener a las personas adecuadas que puedan reconocer el imperio de la Ley, el país cíclicamente cae en esos abismos que las clases oprobiosas y de turbios intereses buscan para reinar en esos espacios, que desgraciadamente en desmedro de las mayorías, resultan ser fértiles a las grises intenciones de estos avivados. De ahí la importancia del Estudio del Derecho Privativo Militar, como una necesidad y obligación de los estudiantes de Derecho; en primer lugar, para entender este campo, un tanto desconocido por la gran mayoría de civiles y otra porque así al conocerlo mejor podríamos ser más puntuales en nuestra apreciaciones, precisos en su cuestionamiento y sólidos en la defensa de la legalidad.

El pretender conocer el origen de la justicia militar de nuestro país, nos obliga a remontarnos en la historia de la humanidad y de los ejércitos, pues desde sus inicios el ser humano se vio en la necesidad de defenderse, inicialmente a nivel individual para luego pasar a proteger su existencia ya sea atacando o defendiendo grupalmente de manera más o menos organizada, de acuerdo con las dimensiones de las empresas bélicas en las que se comprometían, pero que luego de obtener sus objetivos se disolvían tan pronto concluían las guerras. ${ }^{(1)}$ Es en Grecia donde la misma necesidad política de las ciudades estados creó una mag- 
nifica comunidad cívico-militar que bajo el matiz de una sólida organización ciudadana, junto a la férrea disciplina aceptada por estos ciudadanos-soldados les permitiera grandes victorias en batallas como Maratón y Platea durante las Guerras Persas del siglo V a.C.

Es en Roma hacia el 200 a.C., en donde se instituyó por primera vez la conscripción (precedente histórico de lo que hoy se conoce como servicio militar obligatorio) de todos los hombres aptos entre los 17 y los 46 años de edad. Un duro programa de entrenamiento físico dirigido a quienes habían sido seleccionados de niños para convertirse en soldados, aseguró un superior estado de aptitud, sobre todo en los hombres elegidos para servir en las legiones. Son las exitosas campañas de estas tropas que permitieron que el imperio romano se extendiera a casi la totalidad del mundo conocido y ello lo logró gracias a sus conquistas militares, que guardaban en la excelente estructura de sus legiones, la clave de sus exitosos avances, pero por sobre todo la estabilidad de su estado, pues eran épocas muy violentas y la paz, una cuestión muy relativa.

Sin embargo, la relajación de la disciplina militar y los abusos cometidos para el cumplimiento del servicio militar, junto con los problemas causados por las incursiones de tribus enemigas y las luchas sociales intestinas, hicieron necesario que se realizaran reformas militares de largo alcance, adoptadas en el consulado de Cayo Mario. Los soldados ricos y a tiempo parcial fueron sustituidos en el año
104 a.C. por un ejército profesional reclutado para cubrir periodos de 20 años. Es en esta época en donde, probablemente la justicia militar, tiene su génesis de organización pues era sabido que existía la necesidad de mantener disciplinadamente a estas legiones que se encontraban por lo general en lugares lejanos y en constante campaña, por lo que la facultad de administrar justicia que inicialmente estuvo a cargo del emperador fue luego extendida a los "jefes militares", facultando la imposición de sanciones severas a quienes infringieran las órdenes que se impartían. Leyes que se extendieron a todos los pueblos conquistados y que con el transcurso del tiempo se han modificado en atención a los cambios históricos que hoy conocemos. ${ }^{(2)}$

Es en la Edad Moderna en donde la justicia militar, siente la necesidad de experimentar un grado mayor de evolución, que le permitiera ir a la par de los nuevos vientos que el mundo iba tomando, por lo que se vio obligada a establecerse y organizarse como un ente judicial castrense que limitará o dejará en el olvido los excesos que durante y después de las batallas se cometían, no solo con el adversario o pueblo vencido sino incluso con los compańeros de armas vencedores.

A fines del siglo XV, la instauración de los ejércitos permanentes trae consigo la institucionalización de las estructuras militares, tanto en lo que se refiere a ejércitos cuanto a los órganos administrativos que se ocupaban de los problemas bélicos. España fue uno de

\footnotetext{
${ }^{(2)}$ Pablo Sánchez Velarde, "El Ministerio Público en la Justicia Militar" Pág. 387, Anuario de Derecho Penal 2001-2002, Fondo Editorial de la PUCP, Lima-Perú, 2002.
} 
los primeros países europeos que contó con un ejército estable convencional, el núcleo de esta fuerza del siglo XVI eran cuatro regimientos de infantería de 7.000 hombres, dichas agrupaciones por sus efectivos, composición y permanencia, tuvo la necesidad de crear funciones de justicia, que el ejército prontamente implementó inicialmente a través de los maestres de campo y los coroneles de las unidades que posteriormente requirieron la asistencia de auditores, prebostes, alguaciles y verdugos, con cargo de policía, represivos o ejecutivos en lo jurídico o judicial. No existiendo por entonces sino algunas ordenanzas para ciertos ejércitos de operaciones y los bandos militares que determinados jefes daban.

La necesidad de encauzar la justicia privativa del ejército se muestra al aparecer las ordenanzas de Felipe II, del 9 de mayo de 1587 y las ordenanzas del 13 de Mayo de 1587, dadas en Bruselas, por el duque de Parma, gobernador y capitán general de Flandes, "Sobre el ejercicio y administración de la jurisdicción y justicia de este felicísimo Ejército". Su complemento fue, nueve días después el Edicto, Ordenanza e Instrucción sobre el oficio del preboste general y demás capitanes de compañía y barracheles del Ejército que junto a la ordenanza de Felipe IV, del 28 de Junio de 1632, parecen haber regido durante todo el siglo XVII.

Con el advenimiento de Felipe V, y la casa de Borbón, en época de privilegios, excepciones y prerrogativas, la organización del Ejército en lo jurídico se centra sobre una exa- geración del fuero. De ahí que el militar, en campaña y en Paz, se rigiera por leyes generales distintas del elemento civil, como si hubiera dos núcleos o pueblos distintos en un mismo estado. En el siglo XVIII, en su afán de tener un fuero propio, se crea uno para las orgullosas tropas de la casa real; pero la Artillería y los Ingenieros logran cada uno el suyo. La Marina quería también una fortaleza jurídica para sí logrando su propósito recién en el siglo XIX.

Las ordenanzas de 1701 introdujeron el Consejo de guerra o tribunal de capitanes. En 1714 , se dispuso el establecimiento de un Consejo de la Guerra, organizado bajo la presidencia del rey y 15 ministros como vocales. Posteriormente bajo lo dispuesto en la Ordenanza de Felipe V del 28 de diciembre de 1717 quedaron tan solo miembros togados, pero los generales volvieron en 1724 . Es también importante resaltar que a través de las ordenanzas del 10 de enero de 1728 y el 7 de abril de 1745 se dispuso cuales eran las atribuciones del atribuciones del auditor de guerra. Años más tarde una nueva organización se impuso a través de las Ordenanzas de Carlos III, del 22 de octubre de 1768, cuerpo promulgado para ser cumplido inicialmente en España, pero que en 1769 pasó a ser cumplidas en las colonias.

Es sin embargo el 4 de noviembre de 1773 , la fecha formalmente más significativa de la justicia miliar, pues fue ese año tras la creación, por la Cortes de Cádiz, del Consejo Supremo de la Guerra, que se logra el germen de su evolución actual al Consejo Supremo de

\footnotetext{
(a) Más específicamente en 1802, se dictó la Ordenanza Naval que reguló el procedimiento a seguir en la fuerza Naval Hispana.
} 
justicia militar, órgano superior de la justicia castrense, cuya línea de avanzada la integran los consejos de guerra; y sus efectivos pertenecen al cuerpo jurídico militar, posteriormente se dictarían las ordenanzas emitidas por el real decreto de 1793 y la real orden del 19 de noviembre de 1800. En 1802 se dictaría la Ordenanza Naval que regularía el procedimiento a seguir dentro de la Armada Hispana.

Al producirse la independencia de los virreinatos en América, la influencia de la legislación ibérica, no cesó, el estado incipiente de las nuevos países y el caos provocado por la luchas para obtener el poder hicieron que por una cuestión de necesidad, se mantuvieran vigentes muchas de esas normas, en Argentina aún dictada la Constitución Nacional. hasta después del 7 de setiembre de 1881, fecha en que el presidente Roca remitió al Congreso el "Proyecto de Código Penal Militar”, en México las ordenanzas y cédulas referentes a la justicia militar fueron vigentes con algunas alteraciones hasta las reformas en 1882 en que se expidió el primer Código de Justicia Militar, siendo entonces Presidente de la República el General Don Manuel González

En nuestro país, después de su independencia, la situación que se tenía era de confusión y violencia que dio lugar al fenómeno del militarismo, circunstancias que provocó el surgimiento y proliferación de conductas delictivas que ante la necesidad de detenerlas exigió se dispongan medidas muy severas, tomando en cuenta que precisamente quienes encabezaban estos movimientos, no eran militares bisoños, por el contrario, muchos de ellos habían servido en el Ejercito Español, por lo que no les era extraña la organización hispana heredada y su consiguiente verticalidad.

El Reglamentos Provisional, expedido en Huaura en el mes de febrero de 1821, estableció en su artículo $18^{\mathrm{a}}$ la vigencia de todas las leyes, ordenanzas y reglamentos que no se opusieran a los principios de libertad $\mathrm{e}$ independencia; en la Primera Constitución Política del Estado de 1823 su Artículo $121^{\circ}$ señalaba que: "Las leyes anteriores a la Constitución Política de 1823 que no se opongan al sistema de la Independencia y a los principios que aquí se establezcan, quedan en vigor y fuerza, hasta la Organización de los Códigos Civil, Penal, Militar y de Comercio."

Si bien la Carta de 1826 no se pronunció al respecto, el artículo 131 de la Constitución de 1828 consolidó la tendencia de dar continuidad a la vigencia de muchas de las normas constitucionales.

En la Constitución de 1834 se pretendió organizar a la justicia militar, creando un alto Tribunal de Justicia al que se le denominó Consejo Supremo de Guerra, este órgano tenía la facultad de nombrar a los miembros de los tribunales, sin embargo, en 1839, al expedirse la Constitución, no se menciona nada respecto al Tribunal Supremo y se devuelven las facultades jurisdiccionales al presidente de la República, respecto a la justicia militar

La Constitución de 1843 es la primera que contiene una referencia precisa a la justicia militar. El Art. 110, cuando se califica a los tribunales militares como "especiales". La norma señala: "Habrá un Consejo Supremo de la Guerra, compuesto de vocales y un fiscal 
nombrados por el congreso. Asimismo tribunales especiales para el comercio y la mineríala ley determinará los lugares donde deban establecerse estos tribunales especiales, el número de sus vocales y sus respectivas atribuciones".

Sin embargo, y para reafirmar, lo antes dicho, respecto a la influencia normativa de la colonia, en el decreto del 6 de agosto de 1846, dictado durante el gobierno de Ramón Castilla se hace expresa mención como fuente normativa a la Real Orden del 25 de septiembre de 1764 , para decretar que los jueces de primera instancia y los escribanos públicos del fuero común que desempeñaban funciones de auditores de guerra, gozarían del fuero de guerra por el tiempo que sirvieron en tales cargos. Esto fue así, durante la primera mitad del siglo XIX, momento a partir del cual fue siendo sustituida de manera progresiva: en 1852 en el ámbito civil y en 1862 en el ámbito penal.

Asimismo las constituciones de 1856 y 1860 no hacen referencia a la justicia militar pese a lo cual esta funcionó fluidamente, tres años más tarde, el 19 de enero de 1863 una iniciativa del general Juan Antonio Pezet, dispuso la composición de una comisión especial con el objetivo de que las leyes y ordenanzas militares fueran codificadas, concordándolas con la Constitución y la legislación penal; dicho proyecto regiría desde el 1 de mayo de 1865 , pero lamentablemente esta posibilidad no se llegó a consolidar por cuestiones del trauma político-militar que se produjo tras la insurrección del coronel Prado, siendo menester señalar que éste ha sido tal vez el único cuerpo en el que la mayoría de sus codificadores fueron civiles .
Años después, el año 1897 el gobierno de don Nicolás de Piérola contando con la participación de una Misión Militar Francesa, empujó la reorganización del Ejército, el año 1897. La que encabezada por coronel Pablo Clement, presentó un informe sobre legislación militar, administrativa y reglamentos militares. Nombrándose inmediatamente después la que sería la primera comisión encargada de redactar un proyecto del Código de Justicia Militar. Presentado este proyecto, el 10 de diciembre de 1898 fue aprobado por el Congreso y promulgado el $20 \mathrm{del}$ mismo mes. El código comenzó a regir 30 días después de la promulgación, o sea, el 20 de enero de 1899 , teniendo una vigencia de 40 años, sirviendo de base a las cuatro siguientes codificaciones que se han hecho a lo largo de la república (1939, 1950, 1963 y 1980).

La Constitución de 1920, modificada por la ley 5862 de 22 de septiembre de 1927, en su artículo 156, cuando hace referencia expresa en la forma siguiente: "la justicia militar no podrá por ningún motivo extender su jurisdicción sobre personas que no estén en el servicio del Ejercito o Fuerzas de Policía a no ser en caso de guerra nacional", le da el baño de exclusividad que otrora tenía, y es sobre esta base que el Código de Procedimientos en Materia Criminal de ese año, en su Art. 31, sancionó que "...están excluidos de la jurisdicción penal ordinaria ... los delitos puntualizados en el Código de Justicia Militar cuando son cometidos por militares"; esto es, circunscribió la jurisdicción castrense a los militares y a los delitos tipificados en el código de la materia, cuestión que nos obligaría a pensar que tendría una influencia decidida en la futura concepción constitucional. 
Sin embargo la Constitución de 1933 representó un retroceso frente a la Constitución anterior pues extendió peligrosamente la jurisdicción militar señalando que la ley "determinará la organización y las atribuciones de los tribunales militares y de los demás tribunales y juzgados especiales que se establezcan por la naturaleza de las cosas". Es bajo esa plataforma constitucional que se aprueban tres códigos de justicia militar, el de 1939, el de 1950 y el de 1963). El Segundo Código de Justicia Militar, fue aprobado por la Ley No 8991, de 16 de octubre de 1939, con once años de vigencia, dictado al amparo de facultades legislativas delegadas otorgadas por el Congreso Constituyente y bajo el imperio de la Constitución de 1933. El Tercer Código de Justicia Militar fue aprobado por Decreto Ley No 11380, publicado el 7 de junio de 1950 , tuvo como eje la reforma de institucionalización de los Consejos de Guerra permanentes para una sanción eficaz y oportuna, la organización del cuerpo jurídico, la adecuación a un sistema de penas mas flexibles y la imposición de procedimientos mas céleres.

Finalmente bajo el manto de la Constitución de 1933, el Cuarto Código de Justicia Militar, que fue aprobado por Decreto Ley No 14613 del 25 de julio de 1963, en su Art. 229 reconocía la existencia de tribunales militares y dejaba librada su organización y atribuciones a la ley, siempre que sean compatible con "... la naturaleza de las cosas".

El Quinto Código de Justicia Militar de 1980, fue promulgado por Decreto Ley No 23214, del 24 de julio de 1980, es decir pocos días antes de la entrega del Poder de facto del General Morales Bermúdez al Gobierno democrático de Fernando Belaunde Terry, se sustentó en al necesidad de adecuar la legislación militar a la nueva Constitución de 1979, teniendo inspiración en los códigos anteriores, siendo una de las expresiones más vivas de lo anterior dicho, el Artículo $44^{\circ}$ de nuestro Primer Código de Justicia Militar, de 1898 con el Artículo $335^{\circ}$ del código vigente, en la que se evidencia una clara identidad textual

La Constitución, de 1979 avanzó en algo al precisar el ámbito de lo militar y fijar algunas excepciones para el juzgamiento de civiles, aunque sin llegar a ser radical como la de 1920. El Art. 282 modificado por la ley No 24049, estableció, de modo muy similar a la constitución vigente de 1993, aunque esta última amplía la posibilidad de juzgamiento de civiles por la justicia militar, apartándose definitivamente del progresista texto del Art. 156 de la Constitución de 1920. Dicha norma estipulaba: "los miembros de las Fuerzas Amadas y de la Policía Nacional en los casos de delitos de función, están sometidos al fuero respectivo y al Código de Justicia Militar, cuyas disposiciones no son aplicables a los civiles, salvo lo dispuesto en el Art. $235^{\circ}$ - quienes infringen las normas del Servicio Militar Obligatorio están sometidos al Código de Justicia Militar"

Como se puede haber apreciado, ha sido permanente la intencionalidad de los militares de extender interesadamente el alcance de la competencia de sus tribunales tomándola muchas veces cual si fuera una parcela asignada privilegiadamente, amparándose en una normativa peligrosamente ambigua que no propiciaba una delimitación clara y concreta frente a la jurisdicción ordinaria, visión cierta- 
mente anacrónica frente a los nuevos patrones que el mundo moderno tiene y por qué no decir también, por la coyuntura social que vivía el país debido al problema subversivo que afrontó el país desde 1980.

Con el deseo de una mayoría esperanzada, en 1980, nuestro país renovó su promesa casi idílica con la democracia, romance que terminó en 1992, fecha en nuevamente estas mayorías fueron traicionadas en una complicidad siniestra de una cúpula militar corrupta y una fracción de la clase política, que tuvieron en los tribunales militares al brazo ejecutor y de coacción en provecho de los insanos deseos de mantenerse vitaliciamente en el poder al funesto binomio FujimoriMontesinos, la nación nuevamente fue burlada, el estado de derecho nuevamente pisoteado, y la justicia militar, esta vez actuando como protagonista de una de las etapas más negras de nuestra historia, que constituida en un órgano con super poderes, que jamás en su historia tuvo. Resulta difícil no recordar el oprobioso conflicto de competencia del caso de La Cantuta, los excesos cometidos contra dignos oficiales retirados, la serie de atropellos vergonzantes contra los derechos humanos que la justicia castrense cometieron, todo esto realizado bajo extrañas circunstancias de ambigüedad que resultaron ser el abrigo buscado por la impunidad de un gobierno corrupto.

En julio del 2001 El Consejo Supremo de Justicia Militar presentó a través del Ministerio de Defensa, un proyecto de Ley Orgánica y Código de Justicia Militar, que a la fecha aún no han sido consagrada por lo que debieran ser considerados aún como propuestas:
En cuanto al proyecto de Ley Orgánica

- Se declara en forma precisa que los tribunales militares no constituyen organismos de las Fuerzas Armadas y Policía Nacional, afianzando de este modo la independencia y autonomía de los tribunales militares.

- Se establece que los vocales del Consejo Supremo serán nombrados a propuestas de los ministerios de Defensa y del Interior, previo proceso de evaluación conjunta y con la opinión favorable del Consejo Nacional de la Magistratura.

- Se precisa, como organismo de máximo nivel del Consejo Supremo de Justicia Militar, a la Sala Plena, señalando cada una de sus atribuciones, entre las que figuran: resolver los recursos extraordinarios de revisión de sentencias ejecutoriada y conocer las sentencias o resoluciones expedidas por los organismos jurisdiccionales internacionales.

- Con el propósito de racionalizar el trabajo judicial, se considera que el número de zonas judiciales, la extensión territorial y composición de cada una, será establecido en el reglamento orgánico de la Justicia Militar, aprobado por Decreto Supremo. Además se establece que los Consejos de Guerra pueden estar integrados por personal de los tres institutos.

- Se establece que los comandantes Generales de los Institutos de las Fuerzas Armadas y el Director General de la Policía Nacional, deberán atender obligatoriamente los requerimientos de la Justicia Militar, de acuerdo a los cuadros de asignación de personal que se establezca en su reglamento orgánico. 
- Para cumplir con una continua y permanente evaluación de la labor jurisdiccional y administrativa, ha incorporado a la justicia militar, como órgano de control, la Inspectoría General.

- La Dirección Ejecutiva, la Oficina General de Administración, la Dirección de Relaciones Públicas e Imagen Institucional y el Centro de Altos Estudios de la Justicia Militar, se establecen como órganos de apoyo del Consejo Supremo.

\section{Respecto al Código de Justicia Militar}

- Para evitar conflictos de competencia, se precisa el concepto de delito de función, y se constituyen los ilícitos vinculados a la función castrense y al incumplimiento de los reglamentos militares y pasibles de su comisión, solo por personal militar en situación de actividad.

- Se precisa que, la obediencia jerárquica como eximente está limitada al que procede obligado por la ley a obedecer órdenes emitidas por la autoridad o superior y siempre que no actúen en cumplimiento de órdenes ilegales o manifiestamente ilícitas.

- Se ha suprimido la reincidencia y reiterancia como agravante e incluido el Derecho de Gracia como causal de extinción de la acción penal y de la pena.

- En el Título IV se considera los aspectos referidos al Derecho Internacional Humanitario, relacionado con la protección de las personas que no participan o han dejado de participar en las hostilidades, igualmente se consignan normas relativas a la protección de bienes culturales o lugares de culto claramente reconocidos.
- Se tipifica el homicidio por negligencia, con el agravante de la pena, cuando son varias las víctimas o el delito resulta de la inobservancia de reglas técnicas de profesión o de ocupación.

- Para la celeridad y eficacia de los procesos se incorpora, un proceso sumario con todos los medios de defensa prescritos por la ley.

- En acatamiento al principio de legalidad, se suprime la norma contenida en el Artículo $744^{\circ}$ del código vigente, referida a la posibilidad de acudir vía supletoria para efectos de tipicidad al Código Penal, dejándose subsistente esta comisión subsidiaria para la gente dogmática del Código Penal y Código de Procedimientos Penales.

Es menester recordar que en noviembre del 2001, con motivo de la Acción de Inconstitucionalidad interpuesta por el Defensor del Pueblo contra los decretos legislativos número 895 y 897 y la ley 27235 referentes al Terrorismo Agravado, posteriormente llamado Terrorismo Especial, por considerar que estas normas vulneran derechos consagrados en la Constitución Política, el Consejo Supremo de Justicia Militar, en cumplimiento de dicho fallo y a lo dispuesto en el Artículo $204^{\circ}$ de la Constitución Política, resolvió inhibirse del conocimiento de 152 causas, a favor del fuero común, es decir de la Corte Superior del lugar donde se cometieron los hechos delictivos, en el estado procesal en que se encontraba cada uno de los expedientes.

Finalmente debe señalarse que según datos del Consejo Supremo de Justicia Militar desde agosto de 1992 hasta marzo del 2002 fueron 
1346 sentenciados por traición a la patria, a inicios de este año una sentencia del tribunal constitucional respecto a la inconstitucionalidad del tipo pena! de traición a la patria, por lo que ya se ha podido advertir que estos sentenciados deberán tener nuevos juicios en la jurisdicción ordinaria.

\section{CONCLUSIONES:}

1.- La justicia militar en el Perú tiene una fuerte influencia ibérica y ésta a la vez de las justicia castrense romana.

2.- En la gran mayoría de países latinoamericanos a pesar de haber logrado sus independencias, tuvieron que esperar algunos años para poder tener sus propios códigos de justicia militar.

3.- Los códigos de justicia militar Privativos nacionales han tenido en su formación una fuerte influencia de jerarquías militares que muchas veces han dado lugar a que el espíritu de estos códigos hayan dejado mucho que desear en un estricto sentido doctrinario. Asimismo, estos códigos siempre han tenido la pretensión de extender la competencia de la justicia militar lo más posible.

4.- Lamentablemente en la última década la justicia militar fue utilizada para cubrir de impunidad una serie de arbitrariedades y abusos que solo tenían el fin de mantener en el poder a una extraña alianza de militares y políticos, así mismo en muchos casos esta justicia fue manipulada con fines políticos.

5.- Actualmente la justicia militar está experimentando una serie de cambios necesarios, de los que se espera ayuden a mejorar no solo la imagen que se tiene de ella, sino, sobre todo, una mejor administración de justicia castrense con una sólida observación constitucional. 


\section{BIBLIOGRAFIA}

BERNALES BALLESTEROS, Enrique. La Constitución de 1993, Editora RAO S.R.L. Quinta Edición, Septiembre 1999, Lima-Perú.

HURTADO POZO, José. Anuario de Derecho Penal, La Reforma del Derecho Penal Militar, Fondo Editorial 2002 de la Pontificia Universidad Católica del Perú, Primera Edición, Agosto 2002, Lima-Perú.

GACETA JURÍDICA. Código Penal, Gaceta Jurídica S. A..., Segunda Edición, Marzo 2002, Lima-Perú.

CASTILLO PLASENCIA, Jorge W. Diccionario de Justicia Militar, Editorial San GUTIÉRREZ RODRÍGUEZ, Germán Marcos S. A., Segunda Edición, Año 2000, Lima-Perú.

INSTITUTO IBEROAMERICANO DE Jurisdicción Militar y Constitución en IBE- DERECHO CONSTITUCIONAL Íbero América, Editora GRIJLEY E.I.R.L., Primera Edición, Año 1997, Lima-Perú.

SAN MARTín CASTRO, César. Derecho Procesal Penal, Volumen I, Editora GRIJLEY E.I.R.L., Primera Edición, 2da. Reimpresión Julio 2001, Lima-Perú.

ORÉ GUARDIA, Arsenio. Manual de Derecho Procesal Penal, Editorial Alternativas, 2da. Edición, Año 1999, Lima-Perú. 